\title{
Solving a 50 year mystery of a missing OPA1 mutation: more insights from the first family diagnosed with autosomal dominant optic atrophy
}

\author{
Nico Fuhrmann', Simone Schimpf1, York Kamenisch2, Beate Leo-Kottler ${ }^{3}$, Christiane Alexander ${ }^{4}$, Georg Auburger ${ }^{5}$, \\ Eberhart Zrenner ${ }^{3}$, Bernd Wissinger ${ }^{1}$ and Marcel V Alavi*1
}

\begin{abstract}
Background: Up to the 1950s, there was an ongoing debate about the diversity of hereditary optic neuropathies, in particular as to whether all inherited optic atrophies can be ascribed to Leber's hereditary optic neuropathy (LHON) or represent different disease entities. In 1954 W. Jaeger published a detailed clinical and genealogical investigation of a large family with explicit autosomal dominant segregation of optic atrophy thus proving the existence of a discrete disease different from LHON, which is nowadays known as autosomal dominant optic atrophy (ADOA). Since the year 2000 ADOA is associated with genomic mutations in the OPA1 gene, which codes for a protein that is imported into mitochondria where it is required for mitochondrial fusion. Interestingly enough, the underlying mutation in this family has not been identified since then.

Results: We have reinvestigated this family with the aim to identify the mutation and to further clarify the underlying pathomechanism. Patients showed a classical non-syndromic ADOA. The long term deterioration in vision in the two teenagers examined 50 years later is of particular note $5 / 20$ to $6 / 120$. Multiplex ligation probe amplification revealed a duplication of the OPA1 exons 7-9 which was confirmed by long distance PCR and CDNA analysis, resulting in an inframe duplication of 102 amino acids. Segregation was verified in 53 available members of the updated pedigree and a penetrance of $88 \%$ was calculated. Fibroblast cultures from skin biopsies were established to assess the mitochondrial network integrity and to qualitatively and quantitatively study the consequences of the mutation on transcript and protein level. Fibroblast cultures demonstrated a fragmented mitochondrial network. Processing of the OPA1 protein was altered. There was no correlation of the OPA 1 transcript levels and the OPA 1 protein levels in the fibroblasts. Intriguingly an overall decrease of mitochondrial proteins was observed in patients' fibroblasts, while the OPA 1 transcript levels were elevated.

Conclusions: The thorough study of this family provides a detailed clinical picture accompanied by a molecular investigation of patients' fibroblasts. Our data show a classic OPA1-associated non-syndromic ADOA segregating in this family. Cell biological findings suggest that OPA 1 is regulated by post-translational mechanisms and we would like to hypothesize that loss of OPA1 function might lead to impaired mitochondrial quality control. With the clinical, genetic and cell biological characterisation of a family described already more than 50 years ago, we span more than half a century of research in optic neuropathies.
\end{abstract}

\section{Background}

During the first half of the last century, there was a controversial debate about the clinical and etiological unity of hereditary optic neuropathies. Some ophthalmologists

* Correspondence: marcel.alavi@googlemail.com

${ }^{1}$ Molecular Genetics Laboratory, Institute for Ophthalmic Research, Centre for Ophthalmology, University of Tuebingen, Germany

Full list of author information is available at the end of the article favored the idea that the majority of cases are part of the manifestation spectrum of the Optic Atrophy described by Theodor Leber [1], that we now know as Leber's hereditary optic neuropathy (LHON) [2-4]. Others argued that there are different disease entities and suggested discriminating different forms of optic atrophy [57]. In 1954, Wolfgang Jaeger reported his genealogical 
and clinical findings in an extended German family spanning five generations. In this pedigree he could clearly demonstrate that optic atrophy is inherited as a dominant trait including male-to-male transmission. In addition, he pointed out the presence of blue-yellow color vision disturbances in the affected subjects in this family that contrasts to the red-green defect typically present in families with LHON [8]. These features, together with a thorough review of prior clinical reports, enabled him to establish autosomal dominant optic atrophy (ADOA) as a distinct disease entity.

Nowadays, ADOA is a well established disease entity and considered the most frequent hereditary optic atrophy besides LHON. ADOA is clinically characterized by a juvenile onset with a progressive, bilateral reduction of visual acuity, a cecocentral scotoma, temporal pallor of the optic disc and tritanopia as the most typical type of color vision defect $[9,10]$. There is considerable intra- and interfamilial variability in progression of the disease as well as in the severity of the visual impairments, ranging from very mildly affected subjects to legally blind patients [11-13]. Moreover, asymptomatic carriers have been reported in many pedigrees demonstrating reduced penetrance [14-16]. Histopathologic investigations have shown a loss of retinal ganglion cells (RGCs) and thinning of the nerve fiber layer $[17,18]$ which later could be confirmed in an ADOA mouse model [19]. A major locus for ADOA was mapped to chromosome 3q28-3q29 by linkage analysis [20] and subsequently the disease-causing gene OPA1 was identified by our group and an independent group [21,22]. Besides OPA1, two further gene loci for ADOA, OPA4 [23] and OPA5 [24] have been mapped but the underlying genes remain unknown so far. In addition, a small number of families have been reported with $O P A 3$ mutations that cause ADOA associated with early onset cataract [25]. Given the large number of reports of families with $O P A 1$ mutations, the other loci seem to play only a minor role. There are more than 200 OPA1 mutations listed in the eOPA1 database http://lbbma.univangers.fr/eOPA1[26]. Most of these mutations have been identified by conventional, qualitative genetic screening techniques that are insensitive for genomic alterations (i.e. gross deletions or duplications). Only one family with a complete $O P A 1$ gene deletion has been reported in the literature [27] and just recently we have been able to demonstrate that genomic rearrangements may constitute a considerable proportion of causal OPA1 gene mutations [28].

The OPA1 protein is a nuclear encoded, dynaminrelated GTPase which is imported into mitochondria and anchored to the inner membrane of the organelle [29]. Together with mitofusin 1 and 2 it plays a major role in mitochondrial fusion and therefore is important for the maintenance of the mitochondrial network morphology and dynamics [30,31]. Furthermore, OPA1 has been linked to mitochondrial cristae stability and its remodeling in apoptosis [32-34]. How specific OPA1 mutants affect these principal functions has only been sparsely investigated and why mutations in OPA1 cause a mostly selective degeneration of RGCs is unknown. On the other hand there are case reports of syndromic forms of ADOA that include extra-ocular neurological features (sensorineural deafness, ataxia, axonal sensory motorpolyneuropathy, chronic progressive external ophthalmoplegia, mitochondrial myopathy) which have been associated with multiple mitochondrial DNA (mtDNA) deletions $[35,36]$. However, mtDNA deletions can not only be found in muscles from patients with syndromic ADOA, but seem to be present also in muscle biopsies from patients with non-syndromic ADOA [37].

Here we report the identification and re-evaluation of the large family described by W. Jaeger in 1954. Using copy-number sensitive techniques, we have been able to finally identify the disease causing mutation in this family. We provide an update of the pedigree, a clinical follow up of a branch of this family as well as a qualitative and quantitative investigation of mutated $O P A 1$ transcripts and OPA1 protein in fibroblast cell lines established from two patients of this family.

\section{Results}

The original ADOA family described in 1954 was re-contacted with the help of Prof. W. Jaeger (now deceased) and most of the blood samples and medical records were collected in a field study in the mid-90s. The pedigree was updated through several personal interviews with family members, the latest in 2008 (Figure 1). The reconstructed pedigree now comprises a total of 216 family members of whom 57 are affected or were reported to have been affected. In comparison with the pedigree reported in 1954 we noted 19 additional family members affected by ADOA. DNA samples of 22 affected and 31 unaffected family members were collected for this study and fibroblast cultures for functional investigations were established from skin biopsies of two affected subjects (Figure 1, V-24 and V-26).

\section{Long-term follow-up of patients revealed a typical non- syndromic ADOA}

Two affected brothers who were already described in the original report underwent a full ophthalmological reexamination more than 50 years after their initial clinical description (Figure 1A, V-24 and V-26). Patient A (V-24), now aged 69 years and patient $B(\mathrm{~V}-26)$, now 66 years old, were first examined at the age of 15 and the age of 11 , respectively. W. Jaeger reported that both complained of reduced vision in school and already experienced modest loss of visual acuity at this age. Since then visual acuity 


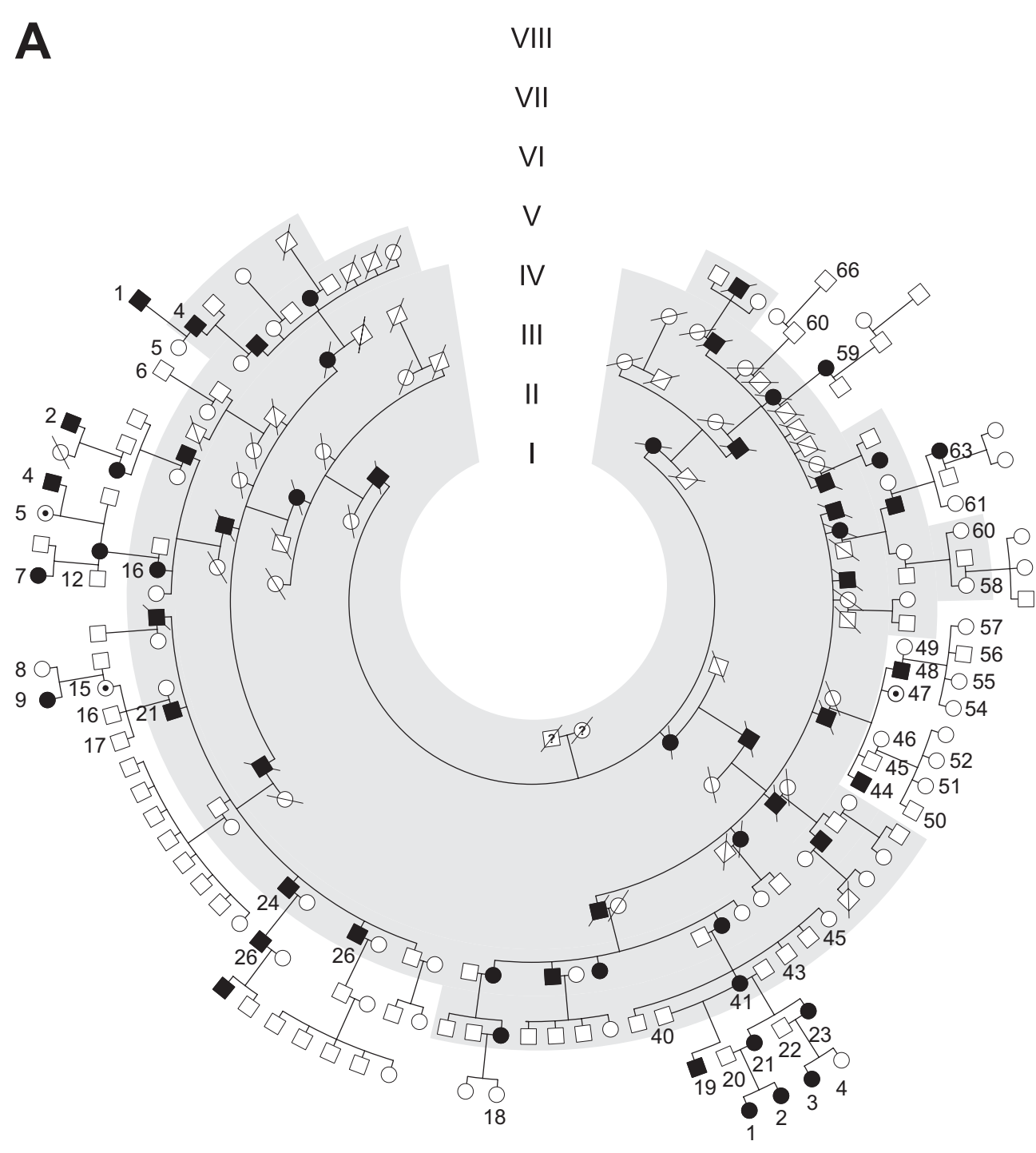

B

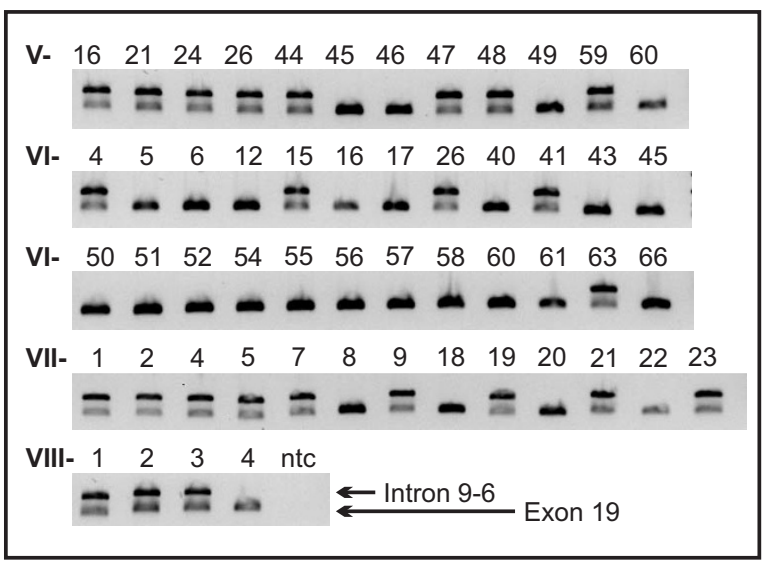

Figure 1 Pedigree of the investigated ADOA family and segregation analysis of the OPA1 exon 7-9 duplication. (A) Updated pedigree of the family. The gray area indicates the original pedigree as described by W. Jaeger 1954. Only persons of whom DNA samples were available are indexed. (B) Segregation analysis applying a PCR assay specific for the OPA1 exon 7-9 duplication. A fragment covering exon 19 sequences was co-amplified as internal control. Subjects are numbered according to the pedigree. Ntc - non template control. 
dropped in both patients from $5 / 25$ and $5 / 20$, respectively, to each $6 / 120$ in both eyes. A slow course of disease progression was also confirmed by self-reports. Neither of them remembered periods of fast loss of visual acuity. Yet both patients have now developed cecocentral scotoma and an optic atrophy progressed to a complete pallor of the optic nerve head, especially of the temporal part of the disc (Figure 2). In comparison with the results of former color vision tests described in Jaeger's original paper, both patients reported further deterioration of their color vision. Using Ishihara's test charts they both could formerly identify at least 5 of the test plates. At the recent examination both patients did not see even the reference plate of the test. Using Stilling-Hertel test charts, patient A could previously identify 11, patient B 13 of the plates. At the recent examination patient A could only identify 2 and patient B 7 plates. Over the period of 54 years, the patients' ability to discriminate between colors has severely diminished.

In addition patient $\mathrm{A}$ suffered from glaucoma; the intraocular pressure (IOP) was $21 / 25 \mathrm{mmHG}(\mathrm{R} / \mathrm{L})$ without medication, while IOP was still in the normal range in patient B (R/L 18/19 mmHG). Patient B received a stent in 2006. Otherwise the medical history was unremarkable and neither of the patients had diabetes mellitus or hearing impairments, typical symptoms in syndromic forms of optic atrophy. In conclusion both patients show a clear and classical non-syndromic ADOA.

\section{Mutation analysis showed a duplication of exons 7 to 9 in the OPA1 gene}

An initial microsatellite marker analysis revealed significant linkage with the OPA1 locus (C. Alexander and G. Auburger, unpublished results). However, subsequent screening of the OPA1 gene by means of DNA sequencing of the coding exons and flanking intron sequences from PCR-amplified genomic DNA did not reveal any putative pathogenic mutation. We therefore applied Multiplex Ligation Probe Amplification (MLPA) to analyse for copy number variations and genomic rearrangements. Indeed, MLPA showed a significant signal increase for the OPA1 exon 8 and 9 probe amplicons in the index patient in three independent experiments (Figure 3A). Using oligonucleotides placed both - forward and reverse - in exon 8 for a long distance PCR we were able to amplify a specific PCR product of approximately $8 \mathrm{~kb}$ in samples of affected individuals only (Figure 3B). Primer walking revealed the presence of a recombined sequence that fuses the 5 part of intron 9 (breakpoint at np194840568, human genome assembly march 2006) with the 3' part of intron 6 (np194832822) of the OPA1 gene (Figure $3 \mathrm{C}$ ). From this we conclude that exons 7-9 plus the flanking intron sequences are duplicated in this family. This mutation was also found in two other ADOA families [28]. In silico analysis revealed Type I transposon elements adjacent to both breakpoints (not shown). We developed a PCR assay that is specific for this duplication and performed a segregation analysis in all family members of whom a DNA sample was available (Figure 1B). We found that all affected family members carry the duplication. In addition, three asymptomatic family members (Figure 1B; V-47, VI-15, VII-5) were mutation carriers. Taking into account that 22 of the 25 mutation carriers are affected we calculate a penetrance of $88 \%$ in this family.

\section{The mitochondrial network is fragmented in patients' fibroblasts}

Since OPA1 is necessary for mitochondrial fusion [30,31], we morphometrically assessed the mitochondrial network in fibroblasts of the two patients after mitotracker staining and confocal imaging. In comparison with wild type control cells we found a significantly decreased proportion of cells with a tubular mitochondrial network when cultured in standard glucose medium (Figure 4A \&4B). Replacement of glucose by galactose in the growth medium to avoid glycolysis reinforced the decrease in cells with tubular mitochondrial network (not shown). These results demonstrate that mutant cells are clearly impaired in their ability to fuse mitochondria. We tested also the integrity of the mtDNA in these cell lines by the amplification of a $12.5 \mathrm{~kb}$ fragment, but did not notice any differences from controls (Figure 4C).

\section{Qualitative and quantitative CDNA analyses revealed an in- frame duplication, a reduced expression level of mutant transcripts and an overall increase of OPA 1 transcripts in fibroblasts}

To study the consequences of this mutation we analysed cDNA from patients' fibroblast cell lines. Thereby we found minor fragments that may represent aberrantly spliced mutant transcripts. Subcloning and sequencing of the major fragment of increased length revealed that this cDNA species had the additional exons correctly integrated as a duplication of $306 \mathrm{bp}$ (c.678-984dup306). This duplication results in an in-frame duplication of 102 amino acids (p.L227_K328dup102). To test if there is an imbalance between the transcripts of the mutated and the WT allele in our patients we quantified allelic transcript levels by pyrosequencing as described previously [38]. Analyses of the OPA1 exon 21 polymorphism (c.2109C > $\mathrm{T})$ revealed a mean percentage ratio for the two alleles of $48.7 \%$ to $51.3 \%$ (S.D. $=1.2$ ). This shows that both alleles are transcribed similar. We also quantified different $O P A 1$ exon-exon junctions in relation to GAPDH by real time PCR to verify this result. If both alleles are transcribed similarly one would expect a ratio of exon 9-7 (x) to exon 6-7 (y) to exon 7-8 (z) of one-to-two-to-three (x : 

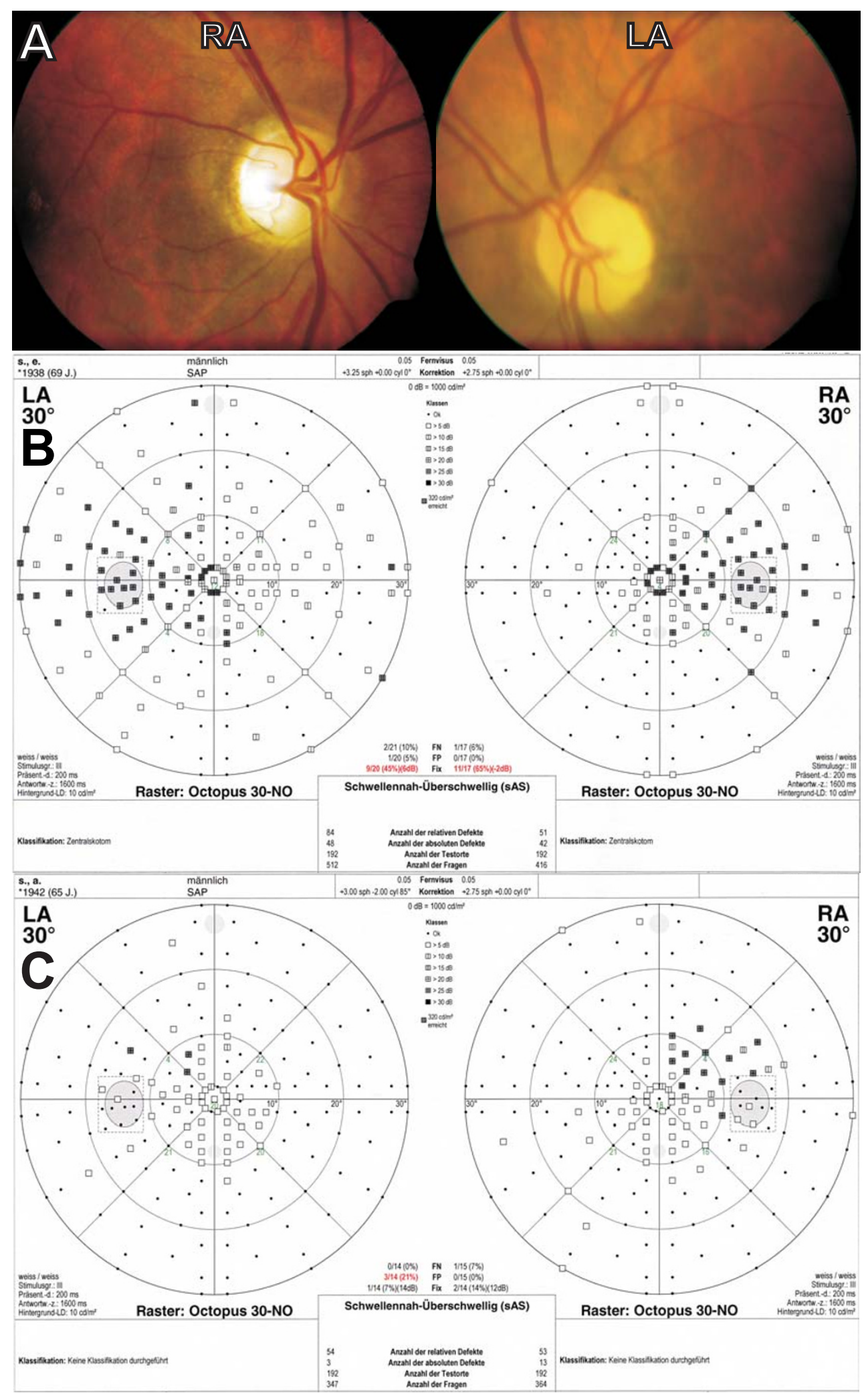

Figure 2 Clinical picture of two patients that had been examined already by W. Jäger. (A) Funduscopy of patient B (V-26) showed pallor of the optic disc with temporal prominence. (B) Visual field of patient A (V-24) showed a clear central scotoma. (C) Patient B showed a decentered central scotoma (excentric retinal locus of fixation, note conjugate displacement of the blind spot). 


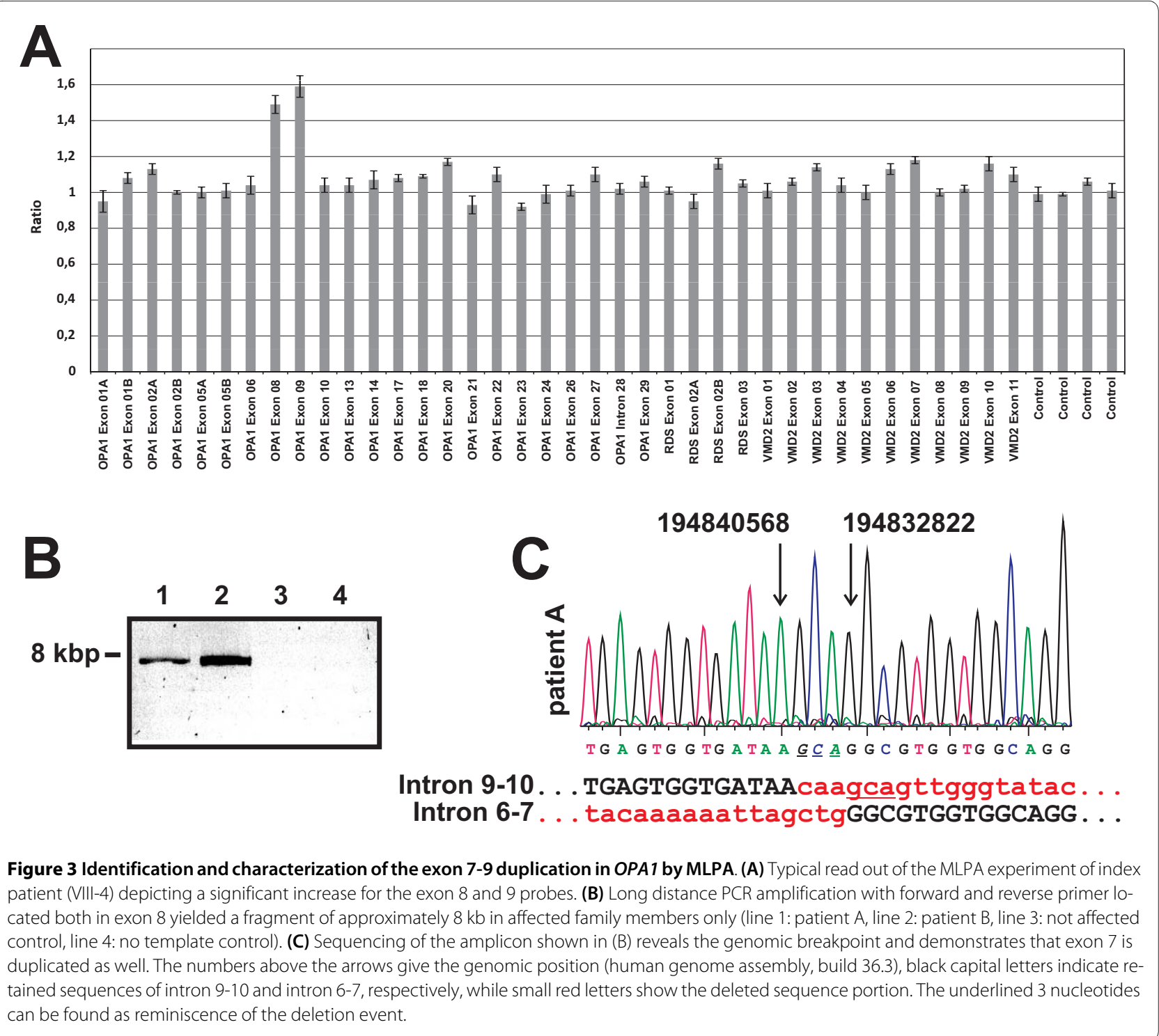

$y: z=1: 2: 3$; see Figure 5A \&5B, line 1 for an overview). However, we found a ratio $\mathrm{x}: \mathrm{y}: \mathrm{z}$ of $0.60($ S.D. $=0.05): 2$ : 2.85 (S.D. $=0.25$ ) in patient $\mathrm{A}$ and a ratio $\mathrm{x}: \mathrm{y}: \mathrm{z}$ of 0.62 (S.D. $=0.07): 2: 2.24$ (S.D. $=0.18$ ) for patient B, respectively (Figure $5 \mathrm{~B}$, line 2 and 3 ). Controls displayed a ratio $\mathrm{y}: \mathrm{z}$ of $2: 1.98$ (S.D. $=0.14$ ) thus proving the reliability of this method (Figure 5B, lane 4). This inconsistency in the results of both assays can be interpreted in a way that a fraction of the transcripts derived from the mutant allele may be spliced correctly (i.e. eliminating the 3 duplicated exons and presenting as wild type) or spliced aberrantly, or both. Of note, the overall steady-state levels of OPA1 transcripts in patients' fibroblasts was more than twofold increased in comparison to the control fibroblasts (Figure 5C).

\section{Qualitative and quantitative protein analysis reveals} reduced levels of OPA 1 and altered processing of the different OPA 1 isoforms

For a qualitative and quantitative analysis of OPA1 protein we used total cell lysates from fibroblast cell lines of patients V-24 and V-26 and four control fibroblast cell lines derived from healthy individuals. The duplicated exons 7-9 of the mutant OPA1 allele result in an in-frame duplication of 102 amino acid residues within the GTPase domain of the OPA1 protein (p.L227_K328dup102), that is expected to increase its molecular weight by $11.8 \mathrm{kDa}$. We consistently found a reduction of all OPA1 protein isoforms in both patients' cell lines in relation to actin (Figure 6A). The different OPA1 isoforms were assigned according to their size as described before [39]. Still we are aware that the assignment is rather hypothetical and 


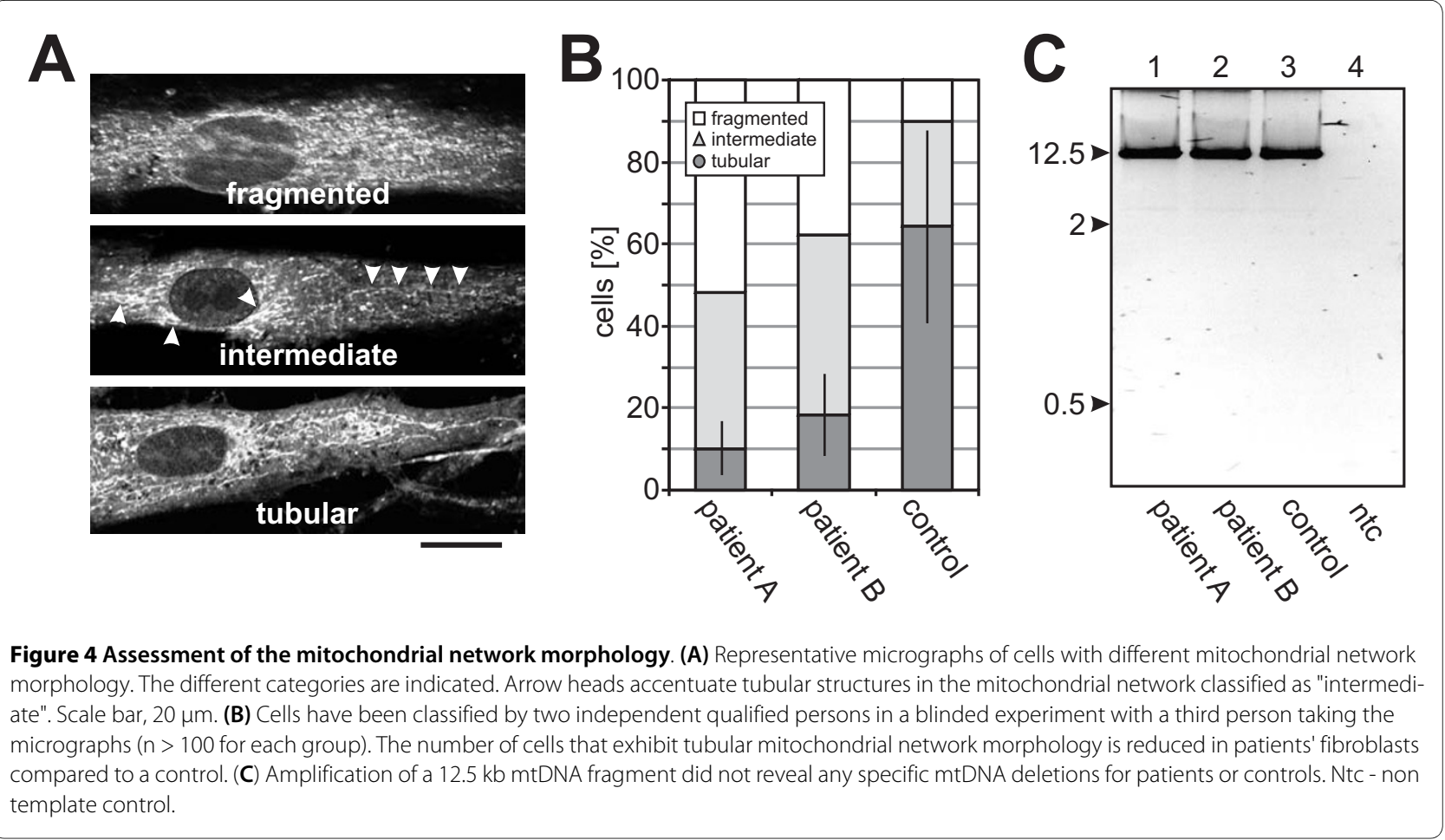

additional experiments would be necessary to define precisely the single bands. However, according to its size the $\mathrm{P} / \mathrm{M}$ band could represent either OPA1 precursor or mutant protein or both. Densitometric analysis of the different isoforms revealed that the S3 and S4 isoforms were reduced to approx. $50 \%$ of their levels in controls while L1, L2 and S5 were reduced not that strong (Figure 6B). The overall OPA1 protein level (excluding the precursor/ mutant form) was reduced to approx. $66 \%$. The observed changes in the relative abundance of the different OPA1 isoforms implicate altered proteolytic processing of OPA1 in mitochondria (e.g. reduced processing when L1 and $\mathrm{S} 3$ constitutes splice variant 7 and L2, S4 and S5 constitute splice variants 1 and 5 as suggested before $[39,40]$ ).

Since we found a reduction of all OPA1 isoforms in relation to actin, we assessed several other mitochondrial proteins (Tom40, CoxIX, ATPase $\beta$, Hsp60) in total cell lysates by westernblot analyses and subsequent densitometric measurements to clarify whether other mitochondrial proteins are reduced in their abundance as well. In comparison to four control fibroblast cell lines we found a reduction of all tested mitochondrial proteins of 20 to $55 \%$ consistent in both patients' fibroblast cell lines (Figure $6 \mathrm{C} \& 6 \mathrm{Ds})$. This finding shows that together with OPA1 other mitochondrial proteins seem to be reduced as well.

\section{Discussion}

Here we report the identification of a large intragenic duplication in the OPA1 gene in a historic family with
ADOA that was first described in 1954 and that was decisive for the definition of ADOA as a separate disease entity [8]. The updated pedigree now comprises a total of 216 family members of whom 57 are affected or were reported to suffer from ADOA. The family thus constitutes probably one of the largest reported in the ADOA literature and may enable further investigations of secondary factors that modulate disease expression and penetrance. Based on our genotyping results we calculated a penetrance of $88 \%$ in this family. This is in line with a previous thorough study of several Australian families with ADOA that reports also a penetrance of $88 \%$ and $82.5 \%$ for the fully ascertained sibships, respectively $[14,15]$. Notably, all unaffected mutation carriers in the family presented herein are females and we previously reported two more unaffected female mutation carriers in other families, one with the same exon 7-9 duplication mutation and one with a complete deletion of the OPA1 gene [28]. All of these unaffected mutation carriers have affected siblings or children which share by definition the same mtDNA haplogroup. This shows that the mtDNA background does not play a major role in governing penetrance in ADOA and we would like to speculate instead about an X-chromosomal inherited QTL or environmental factors. In summary, the studied family presents a well-defined clinical picture for non-syndromic ADOA. There is no evidence of associated extra-ocular symptoms, either in the thorough clinical investigations by W. Jaeger or in our recent re-examinations. 


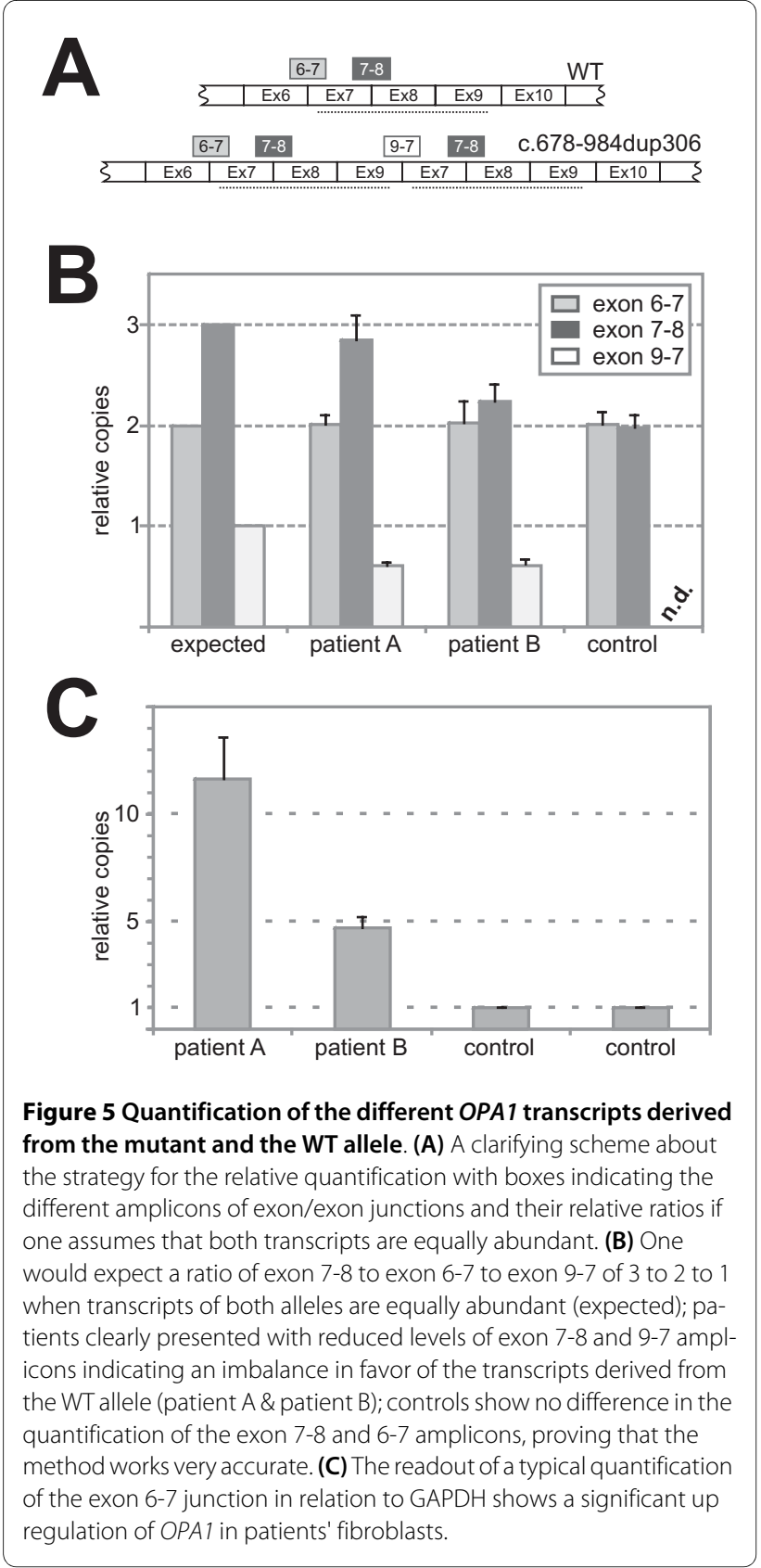

In contrast to other inherited blinding diseases, in ADOA the affected gene is expressed ubiquitously $[21,41]$. With limitations, this offers the possibility to study the consequences of the disease causing mutation on cellular level in any tissue or cell line derived from patients. For the study presented here, we have established two fibroblast cell lines from skin biopsies of the two affected brothers at the age of 69 and 66, respectively and compared them with four different control fibroblast cell lines with the same passage number. Two of the latter were obtained from young children's circumcision specimens whereas the other two derived from skin biopsies of a middle-aged donor and a donor in his late sixties, which served as the primary control. All donors were healthy individuals. Unfortunately we were not able to obtain skin biopsies of the unaffected brothers. However, to our knowledge, donor age has only a minor effect on the replicative lifespan of fibroblasts, in contrast to passage numbers of the cells and/or health status of the donors $[42,43]$, which was both carefully controlled in this study. Donor age shows also only minor effects on mitochondrial enzyme activity [44]. In agreement with this, we didn't find any specific mtDNA deletions in patients' cell lines or control cells that would refer to a premature aging effect of the cells.

Nevertheless, we found a more fragmented and less tubular morphology of the mitochondrial network in the patients' cell lines. Knockout mutants of the OPA1homologue $\mathrm{mgm} 1 / \mathrm{msp} 1$ in yeast show also fragmentation of mitochondria and a reduction of mtDNA content $[45,46]$. A quite similar mitochondrial phenotype could also be observed by down-regulation of OPA1 expression by RNA interference in HeLa cells, which caused fragmentation of the mitochondrial network, loss of mitochondrial membrane potential and disorganization of the mitochondrial cristae $[33,47]$. Spinazzi and colleagues also reported fragmentation of the mitochondrial network in fibroblasts as well as myotubes from patients that harbor a deletion in the GTPase domain of OPA1 (c1410_144314del38) [48].

We found reduced OPA1 protein levels in fibroblasts obtained from patients with non-syndromic ADOA that harbor a 3-exon-duplication in the GTPase domain of OPA1 when compared to controls. This is in line with previous reports on other OPA1 mutations in patients with ADOA, including the deletion in the GTPase domain of OPA1 mentioned above, or Opa1 mouse models, which all report reduced OPA1 protein levels, regardless of the underlying OPA1 mutation [48-52]. Based on this and the description of different families with nonsyndromic ADOA that segregate heterozygous deletions of the complete OPA1 gene [27,28], haploinsufficiency is believed to be a major pathomechanism in OPA1 associated non-syndromic ADOA.

On the other hand our data show that there might be an accumulation of OPA1 transcripts in the patients' cells, which would be in accordance with the observed augmentation of the precursor/mutant protein ( $\mathrm{P} / \mathrm{M}$ band), but in contrast to the reduction of the other OPA1 isoforms in these cells. Previously, we have reported reduced Opa1 protein levels in various tissues obtained from Opa1 mutant mice. In these mice, the Opal transcript levels were not altered compared to littermate controls [49]. Taken together, there seems to be no correlation of the transcript levels and the protein levels for OPA1, which suggests that OPA1 is regulated on protein levels. 


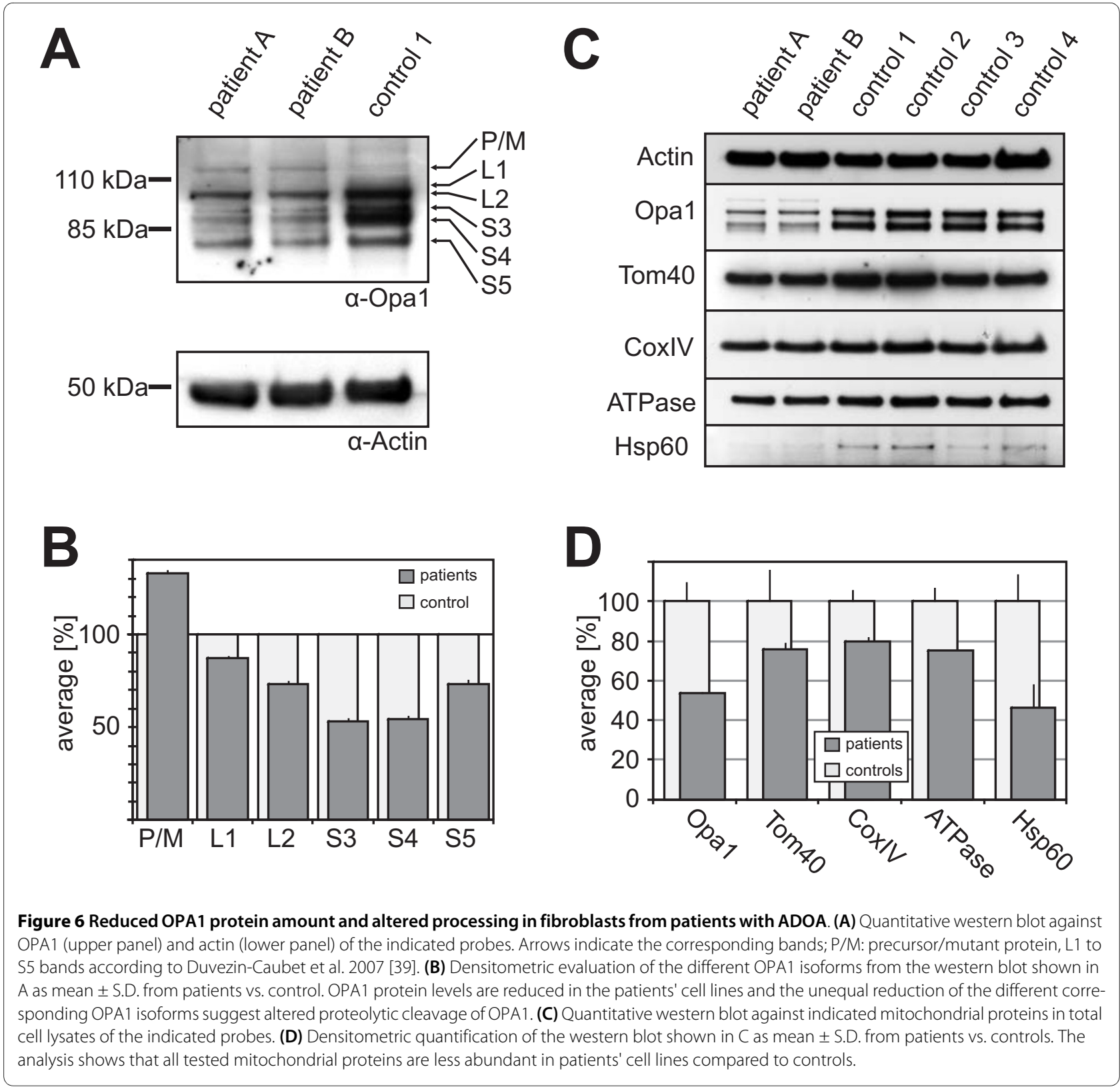

This is supported by a study on OPA1 in conjunction with heart failure that also found no correlation of OPA1 transcript and OPA1 protein levels [53]. In conclusion, this suggests that this 102 amino acid duplication in the GTPase domain of OPA1 leads to altered OPA1 function rather than haploinsufficiency. Taking into account that loss of one complete OPA1 allele leads to a comparable clinical picture (i.e. non-syndromic ADOA) [27,28], one might speculate that OPA1 function is reduced by this particular mutation. Then why and how are OPA1 protein levels reduced in $A D O A$ ? The ubiquitine-proteasome pathway is not involved in the degradation of OPA1 as could be shown in Opal mutant mice [49].
Recently, it has been proposed that mitochondrial fission and selective fusion serves as mitochondrial quality control. Experiments with photo labeled mitochondria revealed that selective fusion separates functional from dysfunctional mitochondria [54-56]. Dysfunctional mitochondria display a reduced membrane potential $\Delta \Psi$ [56], which results in increased proteolytic cleavage of OPA1 [57-62]. As a consequence dysfunctional mitochondria are not capable to fuse anymore and are degraded by autophagy $[54,56]$. According to this, a change in OPA 1 function which reduces mitochondrial capability to fuse should also result in increased mitochondrial degradation by autophagy. Indeed, increase in autophagy has been observed in the optic nerve of Opal mutant mice [63]. 
This might be an explanation for the discrepancy of OPA1 transcript and OPA1 protein levels. In addition, this would be in agreement with the observed fragmented mitochondrial network, the reduced proteolytic processing and the reduction of OPA1 and other mitochondrial proteins in the cell lines from patients with ADOA found in this study. Altered mitochondrial quality control would also explain mitochondrial dysfunction and/or the accumulation of mtDNA deletions as described for patients with ADOA [37].

Still it needs to be shown, if loss of OPA1 function impairs mitochondrial function, which leads to more dysfunctional mitochondria and subsequent removal of these dysfunctional mitochondria, or if loss of OPA1 function impairs mitochondrial quality control directly, which then leads to increased clearance of apparently functional mitochondria, too.

\section{Methods}

\section{Patients and Subjects}

We included 53 family members in this study who have been recruited in a field study in the mid-nineties. An update of the pedigree was obtained from recent personal interviews with various family members. Two of the patients underwent a full ophthalmological examination at the University Ophthalmic Hospital in Tuebingen in 2008. Informed consent was obtained for blood samples and skin biopsies. The study was performed in accordance to the tenets of the Declaration of Helsinki and was approved by the local ethics committee.

\section{Cell culture and staining of the mitochondrial network}

Fibroblast cell lines were established from skin biopsies from patients and compared to 4 different healthy control cell lines with the same passage number. All cell lines were free of mycoplasma contaminations. Cells were propagated in minimal essential medium supplemented with $10 \%$ fetal calf serum (FCS) and antibiotics under standard conditions. For assessment of the mitochondrial network structure, cells were cultured for 24 hours in glucose-free DMEM supplemented with either 10\% FCS and $0.45 \%(\mathrm{w} / \mathrm{v})$ glucose or $10 \% \mathrm{FCS}, 5 \mathrm{mM}$ galactose and 5 $\mathrm{mM}$ pyruvate prior to staining with $10 \mathrm{nM}$ Mitotracker for $45 \mathrm{~min}$ at $37^{\circ} \mathrm{C}$ in the corresponding medium. The morphology of the mitochondrial network was qualitatively assessed by two independent people who did not know either the condition or the origin of the pictures which had been taken by a third person with a fluorescence microscope (AXIO Imager Z1 with ApopTome, Zeiss, Germany).

\section{Isolation of DNA and RNA}

Genomic DNA was extracted from venous blood samples applying standard salting-out procedure, or from culti- vated fibroblasts applying High Pure PCR Template Preparation Kit (Roche, Mannheim, Germany). Total RNA was isolated from whole blood drawn in PAXgene tubes using the PAXgene blood RNA kit (Qiagen, Hilden, Germany). RNA from fibroblasts was obtained using the RNeasy Kit (Qiagen) and subsequently treated with DNAse (New England Biolabs, Frankfurt, Germany). RNA was reverse transcribed using either the Long Range 2 Step RT-PCR Kit (Qiagen) or the Super Script III First-Strand Synthesis System for RT-PCR (Invitrogen, Carlsbad, USA) with oligo-dT-primers or random hexamers.

\section{Multiplex ligation-dependent probe amplification (MLPA)}

MLPA reactions were performed using the P97 and P229 kit from MRC-Holland (Amsterdam, The Netherlands) following the manufacturers' instructions and applying an exactly defined amount of sample DNA (100 ng). Reactions were performed in triplicates and compared with parallel processed controls. The amplified MLPA products were separated on a 3100 Capillary Sequencer (Applied Biosystems, Darmstadt, Germany) and analysed using the Coffalyser spreadsheet (control probe analysis, MRC-Holland).

\section{Breakpoint identification and segregation analysis}

The exon 7-9 duplication was confirmed by long distance PCR, carried out with the TaKaRa LA Taq ${ }^{\text {tix }}$ kit (TAKARA $B I O I N C$., Shiga, Japan) applying both forward and reverse oligonucleotides placed in Exon 8, Exon 8L: 5'GAT GTT CTC TCT GAT TAT GAT GCC-3' and Exon 8R: 5'-CAG ATG ATC TTG CGT ATT ATA ACT GG-3'. The duplication breakpoint was identified by direct sequencing of the ExoSAP (USB, Staufen, Germany) purified long distance PCR product applying a primer walking strategy. Sequencing was done employing BigDye Terminator Chemistry 1.1 (Applied Biosystems) and products separated on an ABI 3100 DNA Sequencer. Segregation analysis was done applying a duplication specific PCR assay with oligonucleotides: Dupl-Ex7-9-L: 5'-TTC TTG ACA GGT TTG ATA TGG AGA-3' and Dupl-Ex79-R: 5'-AAT TAA TGC ATG TCA GTG TCA CCT-3'. In this case PCR was performed using standard Taq polymerase and a short extension time of not more than 30 sec. Numbering of exons and introns was based on OPA1 transcript variant 1 (NM_015560).

\section{Real-Time PCR}

Real Time PCR was performed using cDNA generated from total fibroblast RNA with the following oligonucleotides: RT-Ex6-7-f: 5'-AAG AAC TTC TGC ACA CTC AGT TGA A-3' \& RT-Ex6-7-r: 5'-TTC TAA TCG TTC CAA GAT TCT CTG ATA C-3'; RT-Ex7-8-f: 5'-GGC ATT CAT CAT AGA AAG CTT AAG AA-3' \& RT-Ex78-r: 5'-AAG AAC TTC AGA ATA CAT GTC AAT CAA AG-3'; RT-Ex9-7-f: 5'-GGA GAT GAT GAC ACG TTC 
TCC A-3' \& RT-Ex9-7-r: 5'-TTC CAA GAT TCT CTG ATA CTT CAA CTT AA-3'. Assays were carried out with the Power SYBR Green PCR Master Mix on a real time 7500 PCR instrument (Applied Biosystems). Relative copy numbers were calculated applying the $\Delta \Delta \mathrm{Ct}$ method with GAPDH as reference. The pyrosequencing assay has been described in details before [38].

\section{Amplification of mtDNA}

A $12.5 \mathrm{~kb}$ mtDNA fragment covering most of the coding region was amplified using TaKaRa LA Taq reagents (TAKARA BIO INC., Shiga, Japan) under recommended cycling PCR conditions and applying the following primer pair: MIT-LR1F: 5'-ACA ACC CTT CGC TGA CGC CAT A-3'; MIT-LR2R: 5'-GGT GGT ACC CAA ATC TGC TTC C-3'.

\section{Quantitative westernblot analysis}

For quantitative Westernblot analysis $15 \mu \mathrm{g}$ total protein solubilized in RIPA was separated on NuPAGE 4-12\% Bis-Tris Gels (Invitrogen). Blots were processed for immunodecoration with antibodies against OPA1 (BDTransduction, LA, CA, USA), Tom40 (a kind gift of D. Rapaport, Tuebingen), CoxIV (Abcam, Cambridge, MA, USA), ATPase $\beta$ (BD-Transduction), Hsp60 (Stressgen, Victoria, Canada) or actin (Chemicon, Temecula, CA, USA) applying the ECL chemiluminescence system (Pierce, Rockford, IL, USA). According bands were quantified using ImageJ http://rsb.info.nih.gov/ij/. All protein levels were normalized to actin levels as loading control.

\section{Competing interests}

The authors declare that they have no competing interests.

\begin{abstract}
Authors' contributions
NF performed all genetic analyses including real time experiments; he assisted in the study design, interpreted the data and wrote the paper. SS contributed to the CDNA analysis. YK extracted patients' and control fibroblasts propagated them and provided antibodies. BLK performed all ophthalmological examinations. CA and GA did the field study and provided patients' DNA samples. EZ critically read through the paper. BW critically read through the paper. MVA designed the study, performed all western blot analyses as well as the mitochondrial network analyses, he interpreted the data and wrote the paper. All authors read and approved the final manuscript.
\end{abstract}

\begin{abstract}
Acknowledgements
In memoriam Prof.Wolfgang Jäger. We are indebted to the members of this family for their friendly cooperation and support of this study. We furthermore thank Tao Wei for help with the morphological assessment of the mitochondrial network in stained fibroblasts. We appreciate helpful discussion and comments from Jörg Tatzelt and Konstanze Winklhofer. This work was supported in part by the Friedrich-Spicker-Stiftung, Essen, Germany and the Fritz-ThyssenStiftung Köln, Germany. We thank Judy Howell for carefully reading through the manuscript.
\end{abstract}

\section{Author Details}

${ }^{1}$ Molecular Genetics Laboratory, Institute for Ophthalmic Research, Centre for Ophthalmology, University of Tuebingen, Germany, 2Department of Dermatology, Eberhard Karls University Tuebingen, Germany, ${ }^{3}$ Centre for Ophthalmology, Institute for Ophthalmic Research, University of Tuebingen, Germany, ${ }^{4}$ Department of Neurodegeneration, Max-Delbrück-Center for Molecular Medicine, Berlin, Germany and 5Section Molecular Neurogenetics, Department of Neurology, Goethe University, Frankfurt am Main, Germany
Received: 9 August 2009 Accepted: 14 June 2010

Published: 14 June 2010

\section{References}

1. Leber T: Über hereditäre und congenital-angelegte Sehnervenleiden. Graefe's Archive for clinical and experimental ophthalmology 1871 17:249-291.

2. Cibis P: Beitrag zur Vererbung der familiären Sehnervenatrophie (Lebersche Krankheit). Klin Mbl Augenheilk 1939, 102:

3. Friemann W: Erbliche Opticusatrophie bei Frauen. Graefe's Archive for Clinical and Experimental Ophthalmology 1949, 149:

4. Stählin S: Gibt es eine erbliche Sehnervenatrophie außer der Leberschen Atrophie? Arch Augenheilk 1931, 104:

5. Isayama H: Über eine Art von erheblicher Sehnervenatrophie. Acta Soc ophthalm jap 1934, 38:.

6. Kawakami R: Beiträge zur Vererbung der familiären Sehnervenatrophie. Graefe's Archive for Clinical and Experimental Ophthalmology 1926, 116:

7. Lodberg CV, Lund A: Hereditery Optic Atrophy With Dominant Transmission. Three Danish Families. Acta Ophthalmol (Copenh) 1950, 28:

8. Jaeger W: Hereditary optic atrophy with dominant transmission; with special reference to the associated color-sense disorder. Albrecht Von Graefes Arch Ophthalmol 1954, 155:457-484

9. Jaeger W: Hereditary optic atrophies in childhood. J Genet Hum 1966, 15:312-321.

10. Lorenz B: Hereditary optic atrophy. Ophthalmologe 1994, 91:831-850.

11. Caldwell JB, Howard RO, Riggs LA: Dominant juvenile optic atrophy. A study in two families and review of hereditary disease in childhood. Arch Ophthalmol 1971, 85:133-147.

12. Kline LB, Glaser JS: Dominant optic atrophy. The clinical profile. Arch Ophthalmol 1979, 97:1680-1686.

13. Roggeveen HC, de Winter AP, Went LN: Studies in dominant optic atrophy. Ophthalmic Paediatr Genet 1985, 5:103-109.

14. Cohn AC, Toomes C, Potter C, Towns KV, Hewitt AW, Inglehearn CF, Craig JE, Mackey DA: Autosomal dominant optic atrophy: penetrance and expressivity in patients with OPA1 mutations. Am J Ophthalmo/ 2007, 143:656-662.

15. Toomes C, Marchbank NJ, Mackey DA, Craig JE, Newbury-Ecob RA, Bennett CP, Vize CJ, Desai SP, Black GC, Patel N, Teimory M, Markham AF, Inglehearn CF, Churchill AJ: Spectrum, frequency and penetrance of OPA1 mutations in dominant optic atrophy. Hum Mol Genet 2001 10:1369-1378

16. Li Y, Deng T, Tong Y, Peng S, Dong B, He D: Identification of two nove OPA1 mutations in Chinese families with autosomal dominant optic atrophy. Mol Vis 2008, 14:2451-2457.

17. Johnston PB, Gaster RN, Smith VC, Tripathi RC: A clinicopathologic study of autosomal dominant optic atrophy. Am J Ophthalmol 1979, 88:868-875

18. Kjer $P$, Jensen $O A$, Klinken L: Histopathology of eye, optic nerve and brain in a case of dominant optic atrophy. Acta Ophthalmol (Copenh) 1983, 61:300-312

19. Heiduschka P, Schnichels S, Fuhrmann N, Hofmeister S, Schraermeyer U, Wissinger B, Alavi MV: Electrophysiological and histologic assessment of retinal ganglion cell fate in a mouse model for OPA1-associated autosomal dominant optic atrophy. Invest Ophthalmol Vis Sci 2010 51:1424-1431.

20. Eiberg H, Kjer B, Kjer P, Rosenberg T: Dominant optic atrophy (OPA1) mapped to chromosome $3 q$ region. I. Linkage analysis. Hum Mol Genet 1994, 3:977-980.

21. Alexander C, Votruba M, Pesch UE, Thiselton DL, Mayer S, Moore A Rodriguez M, Kellner U, Leo-Kottler B, Auburger G, Bhattacharya SS, Wissinger B: OPA1, encoding a dynamin-related GTPase, is mutated in autosomal dominant optic atrophy linked to chromosome 3q28. Nat Genet 2000, 26:211-215.

22. Delettre C, Lenaers G, Griffoin JM, Gigarel N, Lorenzo C, Belenguer P, Pelloquin L, Grosgeorge J, Turc-Carel C, Perret E, Astarie-Dequeker C, Lasquellec L, Arnaud B, Ducommun B, Kaplan J, Hamel CP: Nuclear gene OPA1, encoding a mitochondrial dynamin-related protein, is mutated in dominant optic atrophy. Nat Genet 2000, 26:207-210.

23. Kerrison JB, Arnould VJ, Ferraz Sallum JM, Vagefi MR, Barmada MM, Li Y, Zhu D, Maumenee $\mathrm{H}$ : Genetic heterogeneity of dominant optic 
atrophy, Kjer type: Identification of a second locus on chromosome 18q12.2-12.3. Arch Ophthalmol 1999, 117:805-810.

24. Barbet F, Hakiki S, Orssaud C, Gerber S, Perrault I, Hanein S, Ducroq D, Dufier JL, Munnich A, Kaplan J, Rozet JM: A third locus for dominant optic atrophy on chromosome 22q. J Med Genet 2005, 42:e1.

25. Reynier P, Amati-Bonneau P, Verny C, Olichon A, Simard G, Guichet A, Bonnemains C, Malecaze F, Malinge MC, Pelletier JB, Calvas P, Dollfus H, Belenguer $P$, Malthièry $Y$, Lenaers $G$, Bonneau D: OPA3 gene mutations responsible for autosomal dominant optic atrophy and cataract. $J$ Med Genet 2004, 41:e110.

26. Ferre M, Amati-Bonneau P, Tourmen Y, Malthiery Y, Reynier P: eOPA1: an online database for OPA1 mutations. Hum Mutat 2005, 25:423-428.

27. Marchbank NJ, Craig JE, Leek JP, Toohey M, Churchill AJ, Markham AF, Mackey DA, Toomes C, Inglehearn CF: Deletion of the OPA1 gene in a dominant optic atrophy family: evidence that haploinsufficiency is the cause of disease. J Med Genet 2002, 39:e47.

28. Fuhrmann N, Alavi MV, Bitoun P, Woernle S, Auburger G, Leo-Kottler B, YuWai-Man P, Chinnery P, Wissinger B: Genomic rearrangements in OPA1 are frequent in patients with autosomal dominant optic atrophy. JMed Genet 2009, 46:136-144.

29. Olichon A, Emorine LJ, Descoins E, Pelloquin L, Brichese L, Gas N, Guillou E, Delettre C, Valette A, Hamel CP, Ducommun B, Lenaers G, Belenguer P: The human dynamin-related protein OPA 1 is anchored to the mitochondrial inner membrane facing the inter-membrane space. FEBS Lett 2002, 523:171-176.

30. Chen H, Detmer SA, Ewald AJ, Griffin EE, Fraser SE, Chan DC: Mitofusins $\mathrm{Mfn} 1$ and Mfn 2 coordinately regulate mitochondrial fusion and are essential for embryonic development. J Cell Bio/ 2003, 160:189-200.

31. Cipolat S, Martins de Brito O, Dal Zilio B, Scorrano L: OPA1 requires mitofusin 1 to promote mitochondrial fusion. Proc Natl Acad Sci USA 2004, 101:15927-15932.

32. Frezza C, Cipolat $\mathrm{S}$, Martins de Brito O, Micaroni M, Beznoussenko GV, Rudka T, Bartoli D, Polishuck RS, Danial NN, De Strooper B, Scorrano L: OPA1 controls apoptotic cristae remodeling independently from mitochondrial fusion. Cell 2006, 126:177-189.

33. Olichon A, Baricault L, Gas N, Guillou E, Valette A, Belenguer P, Lenaers G: Loss of OPA1 perturbates the mitochondrial inner membrane structure and integrity, leading to cytochrome $\mathrm{c}$ release and apoptosis. $J \mathrm{Biol}$ Chem 2003, 278:7743-7746.

34. Cipolat S, Rudka T, Hartmann D, Costa V, Serneels L, Craessaerts K, Metzger K, Frezza C, Annaert W, D'Adamio L, Derks C, Dejaegere T, Pellegrini L, D'Hooge R, Scorrano L, De Strooper B: Mitochondrial rhomboid PARL regulates cytochrome $\mathrm{c}$ release during apoptosis via OPA1-dependent cristae remodeling. Cell 2006, 126:163-175.

35. Amati-Bonneau P, Valentino ML, Reynier P, Gallardo ME, Bornstein B, Boissière A, Campos Y, Rivera H, de la Aleja JG, Carroccia R, lommarini L, Labauge P, Figarella-Branger D, Marcorelles P, Furby A, Beauvais K, Letournel F, Liguori R, La Morgia C, Montagna P, Liguori M, Zanna C, Rugolo M, Cossarizza A, Wissinger B, Verny C, Schwarzenbacher R, Martín MA, Arenas J, Ayuso C, Garesse R, Lenaers G, Bonneau D, Carelli V: OPA1 mutations induce mitochondrial DNA instability and optic atrophy 'plus' phenotypes. Brain 2008, 131:338-351.

36. Hudson G, Amati-Bonneau P, Blakely EL, Stewart JD, He L, Schaefer AM, Griffiths PG, Ahlqvist K, Suomalainen A, Reynier P, McFarland R, Turnbull DM, Chinnery PF, Taylor RW: Mutation of OPA1 causes dominant optic atrophy with external ophthalmoplegia, ataxia, deafness and multiple mitochondrial DNA deletions: a novel disorder of mtDNA maintenance. Brain 2008, 131:329-337.

37. Yu-Wai-Man P, Griffiths PG, Gorman GS, Lourenco CM, Wright AF, AuerGrumbach M, Toscano A, Musumeci O, Valentino ML, Caporali L, Lamperti C, Tallaksen CM, Duffey P, Miller J, Whittaker RG, Baker MR, Jackson MJ, Clarke MP, Dhillon B, Czermin B, Stewart JD, Hudson G, Reynier P, Bonneau D, Marques W Jr, Lenaers G, McFarland R, Taylor RW, Turnbull DM, Votruba M, Zeviani M, Carelli V, Bindoff LA, Horvath R, Amati-Bonneau $\mathrm{P}$, Chinnery PF: Multi-system neurological disease is common in patients with OPA1 mutations. Brain 2010, 133:771-786.

38. Schimpf S, Fuhrmann N, Schaich S, Wissinger B: Comprehensive cDNA study and quantitative transcript analysis of mutant OPA1 transcripts containing premature termination codons. Hum Mutat 2007.

39. Duvezin-Caubet S, Koppen M, Wagener J, Zick M, Israel L, Bernacchia A, Jagasia R, Rugarli El, Imhof A, Neupert W, Langer T, Reichert AS: OPA1 processing reconstituted in yeast depends on the subunit composition of the m-AAA protease in mitochondria. Mol Biol Cell 2007, 18:3582-3590

40. Olichon A, Elachouri G, Baricault L, Delettre C, Belenguer P, Lenaers G: OPA1 alternate splicing uncouples an evolutionary conserved function in mitochondrial fusion from a vertebrate restricted function in apoptosis. Cell Death Differ 2007, 14:682-692.

41. Bette S, Schlaszus H, Wissinger B, Meyermann R, Mittelbronn M: OPA1, associated with autosomal dominant optic atrophy, is widely expressed in the human brain. Acta Neuropathol (Berl) 2005, 109:393-399.

42. Goldstein S, Moerman EJ, Soeldner JS, Gleason RE, Barnett DM: Chronologic and physiologic age affect replicative life-span of fibroblasts from diabetic, prediabetic, and normal donors. Science 1978, 199:781-782.

43. Cristofalo VJ, Allen RG, Pignolo RJ, Martin BG, Beck JC: Relationship between donor age and the replicative lifespan of human cells in culture: a reevaluation. Proc Natl Acad Sci USA 1998, 95:10614-10619.

44. Schroeder F, Goetz I, Roberts E: Age-related alterations in cultured human fibroblast membrane structure and function. Mech Ageing Dev 1984, 25:365-389.

45. Sesaki H, Southard SM, Yaffe MP, Jensen RE: Mgm1p, a dynamin-related GTPase, is essential for fusion of the mitochondrial outer membrane. Mol Biol Cell 2003, 14:2342-2356.

46. Wong ED, Wagner JA, Scott SV, Okreglak V, Holewinske TJ, Cassidy-Stone A, Nunnari J: The intramitochondrial dynamin-related GTPase, Mgm1p, is a component of a protein complex that mediates mitochondrial fusion. J Cell Biol 2003, 160:303-311.

47. Lee YJ, Jeong SY, Karbowski M, Smith CL, Youle RJ: Roles of the mammalian mitochondrial fission and fusion mediators Fis 1, Drp1, and Opa1 in apoptosis. Mol Biol Cell 2004, 15:5001-5011.

48. Spinazzi M, Cazzola S, Bortolozzi M, Baracca A, Loro E, Casarin A, Solaini G, Sgarbi G, Casalena G, Cenacchi G, Malena A, Frezza C, Carrara F, Angelini C, Scorrano L, Salviati L, Vergani L: A novel deletion in the GTPase domain of OPA1 causes defects in mitochondrial morphology and distribution, but not in function. Hum Mol Genet 2008, 17:3291-3302.

49. Alavi MV, Bette S, Schimpf S, Schuettauf F, Schraermeyer U, Wehrl HF, Ruttiger L, Beck SC, Tonagel F, Pichler BJ, Knipper M, Peters T, Laufs J, Wissinger B: A splice site mutation in the murine Opa 1 gene features pathology of autosomal dominant optic atrophy. Brain 2007, 130:1029-1042.

50. Davies VJ, Hollins AJ, Piechota MJ, Yip W, Davies JR, White KE, Nicols PP Boulton ME, Votruba M: Opa1 deficiency in a mouse model of autosomal dominant optic atrophy impairs mitochondrial morphology, optic nerve structure and visual function. Hum Mol Genet 2007, 16:1307-1318.

51. Olichon A, Landes T, Arnauné-Pelloquin L, Emorine LJ, Mils V, Guichet $A$ Delettre C, Hamel C, Amati-Bonneau P, Bonneau D, Reynier P, Lenaers G, Belenguer $P$ : Effects of OPA1 mutations on mitochondrial morphology and apoptosis: relevance to ADOA pathogenesis. J Cell Physiol 2007, 211:423-430.

52. Zanna C, Ghelli A, Porcelli AM, Karbowski M, Youle RJ, Schimpf S, Wissinger B, Pinti M, Cossarizza A, Vidoni S, Valentino ML, Rugolo M, Carelli V: OPA1 mutations associated with dominant optic atrophy impair oxidative phosphorylation and mitochondrial fusion. Brain 2008, 131:352-367.

53. Chen L, Gong Q, Stice JP, Knowlton AA: Mitochondrial OPA1, apoptosis, and heart failure. Cardiovasc Res 2009, 84:91-99.

54. Mouli PK, Twig G, Shirihai OS: Frequency and selectivity of mitochondrial fusion are key to its quality maintenance function. Biophys J 2009, 96:3509-3518.

55. Twig G, Hyde B, Shirihai OS: Mitochondrial fusion, fission and autophagy as a quality control axis: the bioenergetic view. Biochim Biophys Acta 2008, 1777:1092-1097.

56. Twig G, Elorza A, Molina AJ, Mohamed H, Wikstrom JD, Walzer G, Stiles L, Haigh SE, Katz S, Las G, Alroy J, Wu M, Py BF, Yuan J, Deeney JT, Corkey BE, Shirihai OS: Fission and selective fusion govern mitochondrial segregation and elimination by autophagy. Embo J 2008, 27:433-446.

57. Ehses S, Raschke I, Mancuso G, Bernacchia A, Geimer S, Tondera D, Martinou JC, Westermann B, Rugarli El, Langer T: Regulation of OPA1 processing and mitochondrial fusion by m-AAA protease isoenzymes and OMA1. J Cell Bio/ 2009, 187:1023-1036.

58. Head B, Griparic L, Amiri M, Gandre-Babbe S, van der Bliek AM: Inducible proteolytic inactivation of OPA 1 mediated by the OMA 1 protease in mammalian cells. J Cell Biol 2009, 187:959-966. 
59. Duvezin-Caubet S, Jagasia R, Wagener J, Hofmann S, Trifunovic A, Hansson A, Chomyn A, Bauer MF, Attardi G, Larsson NG, Neupert W, Reichert AS: Proteolytic processing of OPA1 links mitochondrial dysfunction to alterations in mitochondrial morphology. J Bio/ Chem 2006 281:37972-37979.

60. Griparic L, Kanazawa T, van der Bliek AM: Regulation of the mitochondrial dynamin-like protein Opa1 by proteolytic cleavage. J Cell Biol 2007, 178:757-764.

61. Ishihara N, Fujita Y, Oka T, Mihara K: Regulation of mitochondrial morphology through proteolytic cleavage of OPA1. Embo J 2006, 25:2966-2977.

62. Song Z, Chen H, Fiket M, Alexander C, Chan DC: OPA1 processing controls mitochondrial fusion and is regulated by mRNA splicing, membrane potential, and Yme1L. J Cell Biol 2007, 178:749-755.

63. White KE, Davies VJ, Hogan VE, Piechota MJ, Nichols PP, Turnbull DM, Votruba M: OPA1 deficiency associated with increased autophagy in retinal ganglion cells in a murine model of dominant optic atrophy. Invest Ophthalmol Vis Sci 2009, 50:2567-2571.

doi: $10.1186 / 1750-1326-5-25$

Cite this article as: Fuhrmann et al., Solving a 50 year mystery of a missing OPA1 mutation: more insights from the first family diagnosed with autosomal dominant optic atrophy Molecular Neurodegeneration 2010, 5:25

Submit your next manuscript to BioMed Central and take full advantage of:

- Convenient online submission

- Thorough peer review

- No space constraints or color figure charges

- Immediate publication on acceptance

- Inclusion in PubMed, CAS, Scopus and Google Scholar

- Research which is freely available for redistribution

Submit your manuscript at www.biomedcentral.com/submit
C) Biomed Central 